To cite this article:

Dickinson, J.E., 2014. Time, Tourism Consumption and Sustainable Development. International Journal of Tourism Research, 16(1), 11-21.

\title{
Time, Tourism Consumption and Sustainable Development
}

\begin{abstract}
The availability of time has played a pivotal role in the analysis of tourism. An examination of social theory and time suggests tourists experience time in multiple ways which has implications for the traditional temporal and spatial reference frame. This paper calls for a better understanding of 'time' in tourism and sets the agenda for further research into time and the sustainable development of tourism. It analyses the role of time in shaping tourism consumption and illustrates the challenges posed by new temporal understandings and distance concepts to create less greenhouse gas dependent tourism in our society.
\end{abstract}

Keywords: time; consumption; travel; distance; climate change; sustainability

\section{INTRODUCTION}

Tourism is an example of consumptive orientated leisure where demand, provision, improved technology and infrastructure is driving tourists further away, faster, more often, for fewer days per trip. Analysis of tourism's contribution to greenhouse gas (GHG) emissions shows that travel to a destination is a key contributor. Estimates for the overall contribution of travel to tourism's GHG emissions are about 75\% (Scott, Peeters \& Gössling, 2010). Air travel contributes around $40 \%$ of the carbon dioxide emissions from tourism travel (Scott et al., 2010), despite accounting for only 17\% of global tourist trips (Bows, Anderson \& Peeters, 2009). Car travel is also a significant contributor, with the rather broad category of leisure related travel accounting for 40-50\% of travel in developed countries (Becken and Hay, 2007). This represents a significant share of the $13 \%$ contribution to GHG emissions by the transport sector (Gössling and Upham, 2009). However, air travel is by far the fastest mode for medium to long haul travel, and the trend is for both the number and length of flights to increase (Peeters, 2007; Peeters \& Dubois, 2010), while car travel has the largest share of tourism overland travel due, in part, to its perceived speed and ability to fluidly negotiate scheduling constraints.

Growth in tourism consumption raises important questions about the production of GHG emissions. As travel technology has developed and speeds increased, this enabled people to travel faster and therefore further at lower cost within the time a tourist has available. This opened up new destinations to mass markets. Fundamental to this development is the interaction between time, travel speed and travel distance. These issues are rarely taken into account in discussions to develop sustainable tourism policies. Researchers examining time have both questioned the quantity of time available for leisure use and reconsidered the nature of time itself, recognising multiple temporalities, paces and rhythms. This calls for research to consider the relationship between time and sustainable 
mobility. In exploring these elements, this article unpacks assumptions and highlights emerging research problems for the theoretical re-appraisal of the relationship between tourism and time. In doing so we consider how emerging temporal conditions might provide opportunities for more sustainable tourism consumption practice to reduce GHG emissions.

In developed countries, industrial, or clock time, has dominated social life since industrialisation. Recreation and tourism emerged from the social institution of clock time as it was increasingly recognised that 'time out' from work was essential for human well-being and increased productivity of the work force. Since the emergence of statutory work hours regulations in Europe and other industrialized nations, the hours worked per week have gradually decreased while annual holiday entitlement has increased. Together with rising disposable income, this has led to rapid growth of the tourism sector. In the last two decades of the twentieth century however, the decrease in hours worked has been less marked in Europe, a trend noted earlier in the USA. Since the 1990s it has been widely discussed that for some groups of workers, working hours maybe on the increase (Castells, 2000). Overall this increase in working hours has been masked by the widespread entry of women to the labour market who work, on average, fewer hours than men (Echtelt, Glebbeek \& Lindenberg, 2006).

Concurrently, changing working practices, particularly linked to post-Fordist organisations, together with the rise of the Network Society (Castells, 2000), have led some sectors of society to experience time in a different way; referred to as timeless time (Castells, 2000), fragmented time (Klein, 2004) or instantaneous time (Urry, 1994). For many educated professionals time has become more relative and contextual rather than a linear, measurable concept as work and leisure spaces become blurred. At the same time, across Western society as a whole, a growing proportion of the population have experienced greater temporal fluidity, facilitated by information technologies, which has altered the traditional frame of temporal and spatial reference and the need for copresence to perform key tasks (Castells, 2000). As a result society has entered a period where two phases of time co-exist and mix which has implications for tourism since time, as measured by clock time, has played a pivotal role in the emergence and most of the development of tourism. In 1996 Deem suggested the study of leisure had a long way to go to engage more fully with debates about social theory and time, yet relatively little has been written in recent years specifically relating to tourism and time. While the availability of time has traditionally framed our understanding of the opportunity for tourism, the emergence of new theoretical perspectives on time, both within tourism and other disciplines, may revise this position.

Three core topics are explored. First, drawing on a growing body of theory analysing new concepts of temporality, the paper begins by considering how relative and variable understandings of time structure the tourism experience and the demand for mobility. This sets the scene for subsequent analysis. 
Second, since a cost, distance, time model has dominated the analysis of travel, the time bound structures in late modernity pose a significant constraint when choosing modes of transport (Dickinson, Robbins \& Lumsdon, 2010). However, as we demonstrate, contemporary analysis questions this perspective and emerging concepts such as slow travel reveal alternative directions. In the typical model, travel time is constructed as a disutility and time spent travelling is viewed as wasted time. It is not clear, given the wide range of tourism choices, why society has embraced the desire to travel ever greater distances for a given amount of travel time spent, which has changed little during the past four decades (see for example, Hupkes, 1982; Metz, 2008; Peters, 2006; Schäfer and Victor, 2000). People have used the higher speed of new transport technology to increase the distance travelled as opposed to visiting places nearer to home, more quickly, while saving time for leisure activities. This reflects a Western, and to some extent Asian, tendency to value the special, the biggest and the furthest higher than other goods, with mobility and speed at the heart of modernity (Germann Molz, 2009). Additional time, income and improved travel infrastructure has enabled an increasing, though still small, proportion of the world's population to travel further and more often. This has led to various global inequalities. For instance, while about $85-90 \%$ of the world population does not engage in international travel due to lack of time and wealth (an estimate based on UNWTO (2011) and United Nations (2011)), it is the poor who are differentially impacted by climate change. Füssel (2010) shows the existence of a 'double inequity' at the nation level, meaning those nations benefiting least from GHG emissions are most vulnerable to the impacts of climate change. Faster travel can not only bring greater direct environmental impacts, it also enables productivity gains and further consumption. With the longer distance travel now undertaken by tourists, air travel is the only realistic alternative for many destinations and source market combinations. Given the apparent significance of time it is important to consider how contemporary perspectives on temporality might alter our core understandings of tourism travel.

Third, drawing on wider debates from the literature on time and sustainable consumption, the paper explores and questions the link between work, time and tourism consumption. Hayden and Shandra (2009) have linked shorter working hours to positive environmental benefits; however, there is a need for more careful analysis of work hours in relation to tourism consumption. If work hours are decreasing, this may reduce the need for fast transport, but at the same time it may simply increase the number of trips. Increasing work time would almost certainly cause more time pressure and thus the choice of fast transport, but may also reduce the travel frequency. However, new temporal frames associated with the Network Society are enabling a more fluid interpretation of time, new forms of mobility may free up time for travel, thus negating the direct time constraint assumed above.

\section{TIME AND TOURISM}

In society today it is hard to conceptualise time in any other way than a measure of the 24 hour day, yet in earlier times this classification would have been alien, as a task 
orientated perspective characterised pre-industrial life (Breedveld, 1996) and the concept of time was vague (Schor, 1991). However, this is not to say that time did not matter as people would still feel the passing of time and consider how long to spend on a task and how many tasks to do. Time always exists as a physical entity independent of humans. Travel, for example, obeys Newton's laws of physics, but the way people conceptualise this physical idea of time as 'clock time' is, "really only a particular form of time at a particular stage of societal development and self-regulation, even though we may sometimes be convinced that no other conceptions of time (such as those based on seasons or 'natural' rhythms) are valid" (Deem, 1996, p.16). This emerged around the $13^{\text {th }}$ to $14^{\text {th }}$ century through the more widespread use of clocks, which provided a means to commoditise time to manage labour (Schor, 1991). While this time system pervades most parts of the world, its authority varies depending on the cultural context. The emergence of clock time was not abrupt as different time phases necessarily overlap (Klein, 2004). While clock time is inevitably embedded into a high-tech society, today society is again witnessing the emergence of a new time phase and, as this is assimilated into society, two time conditions overlap.

New technology has, to some extent, released people from the constraints of space and time: transport has become ever faster, while ICT and communication technology make it possible to be in one place physically, but to directly communicate with everyone everywhere in the world (Frändberg, 2008; Klein, 2004). The ongoing sociological debate about time delivered several new conceptions of time, for example, 'timeless time' (Castells, 1997), fragmented time (Klein, 2004) and 'space of flows' (Castells, 1997). The extent to which a new phase of time has permeated society is, as yet, unclear. While post-Fordist work practices are predominantly a middle class, professional phenomena, elements of a new temporality, such as 24 hour on-line shopping, banking and social networking, have permeated most sectors of society. Also, within the EU, most employees have achieved some capacity to negotiate more flexible working practices even if these are still structured by clock time. Given the central role played by time in society this calls for a theoretical reappraisal of its role in the structuring of tourism.

\section{Tourism, temporality, pace and mobility}

In many explanations of tourism, time is an integral element. Tourism, as a category of leisure, can be positioned in binary opposition to work (see, for example, Breedveld, 1996; Gershuny, 2000), although only if tourism is defined as leisure as opposed to business travel. Though this is a narrow explanation of tourism, the number of hours at work, the amount of holiday entitlement and the blocks of time available out of work have traditionally structured the opportunity for tourism. Tourism as time out of work even pervades forms of tourism such as 'lifestyle travellers' (Cohen, 2011) where tourists often work intermittently to facilitate extended trips. Our experience of this 'bought' time plays a role in the tourist experience. In broad and simplistic terms, holidays are the "times for our lives" (Ryan, 1997 from Richards, 1998, p.146), 'time out' (Elsrud 1998), and "offer relief from time and place, two of the key constraints of everyday life" 
(Richards, 1998, p.146). Here tourism is seen as an escape from the temporal constraints imposed by everyday life and provides the chance to have 'own time' which is variable depending on the individual context. A tourist reading on the beach slows down but some holidays are overloaded with things to do and demanding tour operator schedules. The latter belong in the time paradigm of 'more is better'.

Whether tourists are ever really able to escape from temporal constraints is contested. Most holidays have a time limitation after which people must return home and tourists are surrounded by workers bound by the temporal constraints of tourism institutional working practices (Minca, 2009). Tourism is also structured by the schedules of trains, airplanes, meal times and attraction opening hours. Tourists need to determine not only how much time is needed for travel to reach a destination or attraction but also how much time should be allocated to experience the place visited (Haldrup 2004). Germann Molz's (2010) analysis of round the world travellers illustrates the perceived significance of visiting places at the right time. This might be the appropriate season, to avoid high tourist numbers, or to visit emerging destinations before they are over run by mass tourism. Her analysis demonstrates a significant level of tourist anxiety in time allocation and correct pacing of trips. Meeting these schedules can be a significant logistical undertaking for some tourists which Larsen, Urry \& Axhausen (2007) suggest is in part a work activity. Back in 1970 Linder noted that leisure was becoming less leisurely as leisure participation has intensified with more practices condensed together (Jäckel and Wollscheid, 2007).

As an extension to this dualistic picture of work and tourism, in which time is seen simply as a constraint, a growing body of theory is seeking to understand the multiple temporalities of tourism. For example, tourists experience the unfolding of a place over time during the course of travel, encountering different places at different paces (Haldrup, 2004). The pace of the encounter is part of the constituent of place (Bærenholdt, Haldrup \& Larsen, 2004; Germann Molz, 2010) and destinations are fluidly encountered and created. Different styles of movement (such as travel mode) and different paces (speeds and rhythms) are encoded to some degree in the destination visited. Thus mode and style of travel influences rhythms that create a sense of place (Edensor, 2010). In addition, tourism explicitly seeks out different times (Germann Molz, 2010). The experience of time is variable (Adams, 1995) and temporal differences are apparent in destinations due to different cultural expressions of time and the daily rhythms of life. For example, tourists might seek the past by visiting a place seemingly rooted in a more traditional way of life, and one often revealing gross global inequality, or one structured through memories of past visitation (Bærenholdt et al., 2004).

Related to the above points are also moral, ethical and political dimensions to the temporality of tourism. Institutionally imposed rhythms become habitual (Edensor \& Holloway, 2008). These can become routinized to such an extent that we are often unaware that particular rhythms exist (Adams, 1995). These influence mobility and travel choices as they are embedded in the norms of tourist behaviour. Combined with other structural forces, such as the transport infrastructure available (Dickinson et al., 2010), 
temporal rhythms potentially limit the choices available to tourists. Linked with the importance of spending 'enough' time in particular places, temporality becomes morally charged and the availability of time budgets is imbued with power (Germann Molz, 2010). Aligned with this is the unevenness of access to speed (Edensor, 2010). At a global scale few have access to fast forms of transportation and even within Western society there is considerable travel inequality (Holden, 2007). In order to explore these issues further, the next section examines wider debates on time and sustainable consumption.

\section{Sustainable consumption, work, time and tourism}

Several studies have examined the role of time in sustainable consumption more broadly. On the one hand, Victor (2010) suggests that we will need a steady state economy, or even de-growth, to deal with environmental problems and improved productivity, with increased leisure time as an important factor. Providing some optimism here, analysis suggests that working shorter hours might bring about environmental benefits (Hayden and Shandra, 2009; Sanne, 2002). Reducing work hours at constant productivity would limit GDP which is a major driver of eco-footprints. Working fewer hours may also facilitate more sustainable, time consuming, lifestyle practices such as cycling or using public transport. On the other hand, given the energy intensity of some forms of tourism (Gössling, Peeters, Ceron, Dubois, Patterson \& Richardson, 2005), if more leisure time increases tourism consumption at the cost of 'average consumption' this adds to unsustainable development. Conversely, working long hours results in time scarcity, which might drive people to less sustainable consumer choices such as convenience goods.

A review of the average annual hours worked (Table 1) indicates most countries saw a drop in work hours from 1970 to 2000, however a relatively stable picture emerges over the last 10 years. As data for part-time workers may mask increasing hours for full-time workers, a detailed analysis of the last 10 years data for UK full-time workers (Table 2) suggests a fairly stable pattern of weekly hours for most categories of employment with a small drop in hours for some. However figures can mask over-employment, the phenomenon of working more hours than desired and there is a well-known gap between actual and preferred work hours (Echtelt et al., 2006). One explanation for overemployment is the 'social rationality approach' (Echtelt et al., 2006) or 'social contagion' (Brett and Stroh, 2003) where workers make social comparisons and feel they need to be seen to be working more hours and feel obliged to finish tasks by a deadline so as not to let down colleagues or be perceived badly. Linked to this concern for status is also the desire to work more hours to enhance promotion opportunities (Golden, 2009). These elements are particularly a feature of post-Fordist work structures where responsibility for completing tasks and working hours is shifted to the worker from the employer (Echtelt et al., 2006). Even among less skilled tourism employees there is evidence that the workforce is controlled by the gaze of other employees (Minca, 2009). For many professional workers the ability to tap into a network of information outside of work has led to an acceleration of this process (Castells, 2000), with evidence that a larger proportion of paid work is undertaken at home (Holliday, 1996). 
[Table 1]

[Table 2]

A further explanation for over-employment arises from leisure studies where it is suggested that leisure is no longer the opposite of work, as once portrayed by Parker (1983), as work structures have changed, many jobs are more fulfilling and work can even be seen as an emotional respite from home (Brett and Stroh, 2003). Veijola (2009, p. 101) suggests that "contemporary working life in the Westernized world seems to have become more and more tourist-like: being largely based on information, communication, hospitality and experiences". Within tourism settings, where work and leisure spaces are blurred, there has been an intensification of tourist workers' lives as their work becomes their life (Veijola, 2009). For some this can provide an idealized lifestyle (Minca, 2009).

Though it is difficult to find clear empirical evidence of change in work time flexibility, with the Labour Force Survey suggesting little change in the variability of hours worked per week (Table 3), unpaid overtime has gone up from 1991 to 2010 with standard deviations indicating a wide spread of overtime hours in 2010, indicating some workers take on considerable overtime (Table 4). However, in other respects work time has fallen. For instance, there has been a shortening of the number of years people work as they enter the work force later due to higher education. There has also been a decline in employment of over 50s (Castells, 2000), although recent economic forces are pushing the state retirement age higher in the EU.

[Table 3]

[Table 4]

While the picture on over-employment is mixed, several analyses suggest that working long hours drive people to spend money to compensate (Reisch, 2001) leading to over consumption of "products that generate feelings of comfort rather than pleasure" (Gratton, 1996, p. 102) and Schor (1996, p. 16) suggests increasing working hours push people to much shorter and frequent holidays as "they feel they need it because they are highly stressed out, burned out, and fatigued, and feel they just have to get away." Data supports this shift (see, for example, Alegre and Pou, 2006) as the average length of holidays has fallen. However, recent empirical evidence suggests length of stay is not necessarily related to available time and may be better explained by destination attributes (Gemann Molz, 2010) and tourist characteristics (Barros and Machado, 2010). Time, therefore, is not only a constraint in terms of its overall availability, the experience of time also governs emerging practice. Tourists also become habituated to particular temporal rhythms both within their mobility and when planning mobility. In addition, other social institutions, such as school holidays, both fix periods for holiday and limit the time available, as does the tendency to take holidays in one or two week blocks (Alegre and Pou, 2006).

\section{The experience of travel time}


There is some consistency in the time people are willing to allocate to travel. Over a certain distance there is a rapid decay in tourist numbers to an attraction (Prideaux, 2002) and the development of transport infrastructure has played a significant role in destination development (Prideaux, 2000). Within this model, which is increasingly contested (Holley Jain \& Lyons, 2008), travel time is seen as wasted time, though greater distance and time commitment can be overcome by the strength of destination attraction and society's desire and excitement for the exotic, with recent studies suggesting this may be addictive (Cohen, Higham \& Cavaliere, 2011). However, given the strength of society's institutionally embedded time structures, travel distances have predominantly increased through technological developments resulting in greater speed of travel (Peeters \& Landré, 2012), one outcome being increased GHG emissions.

Time limitations have become a pervasive feature of arguments in the industry, media and academia that favour car and air travel. The argument stands in some context but is also a perceptual barrier. An obvious example is the increasing speed of international train travel. Evidence suggests tourists are overly pessimistic about travel times by modes other than air travel (Dickinson et al., 2010). The perception of travel time is therefore a limitation in its own right and is influenced by geographic distance, travel costs, familiarity with travel route, attractiveness of route, mode of transport, rational for trip (business or leisure) (Wittmer and Laesser, 2010), habituation and social norms (Hares, Dickinson \& Wilkes, 2010).

The level of 'time sovereignty' (Cass, Shove \& Urry, 2004), that is the control over temporal flexibility, is also socially differentiated. Some sectors of society have much greater freedom to dictate their temporal arrangements of travel than others. The transport poor, who are more reliant on public transport, find their lives and leisure opportunities determined by the temporal availability of transport and the ways in which time and space patterns govern people's lives can lead to exclusion from certain activities (Cass, Shove \& Urry, 2005). In this respect time is one of several dimensions controlling access and creating travel inequality, the others being financial, physical and organizational (Cass et al., 2005). The access to 'time shifting' devices, such as the car, is desirable since they offer superior time sovereignty (Southerton, Shove \& Warde, 2001) despite the negative environmental externalities.

People's social circumstances also frame tourism decisions and there are identity issues for those who opt to utilise time differently. There is much cultural significance attached to the consumption of positional goods such as holidays (Reisch, 2001) and Jackson (2005) suggests it is foolish to appeal to people to consume less given the symbolic nature of these goods. Status is attached to travelling further and faster, and visiting the right places (Germann Molz, 2010), hence less travel might be seen as inferior. There is also desire for, and thrill of, speed (Germann Molz, 2009). Coupled with the way consumer decisions are locked into day to day practice (Jackson, 2005), this is a negative force for sustainable tourism. 
Elsrud (1998, p. 309) suggests the journey maybe a time when the "traveller regains control of her own time and movement". Slow travel represents a movement challenging the idea of the faster being better syndrome. It has emerged from the wider slow movement (Dickinson and Lumsdon, 2010) and is associated with a re-conceptualization of time and a "subversion of the dominance of speed" (Parkins 2004, p. 363). Slow travel is also a less consumptive form of tourism associated with environmental stewardship (Germann Molz, 2009), where air and car travel is avoided in favour of slower overland modes of transport and presents a scenario where tourists might reduce GHG emissions. This makes it an interesting case to consider in terms of new conceptualisations of time. Parkins (2004) suggests different temporalities make up every day life and slow living points to an alternative understanding of time itself. "In a non-stop society, leisureliness and unhurriedness are becoming attractive" (Reisch, 2001, p. 376).

Dickinson et al. (2010) found some evidence that slow travellers rationalise travel distance decisions differently to other tourists, with less focus on getting to a specific destination and a stronger focus on the travel mode and where it is feasible to go. Taking more time to do something well is an aspect widely embraced by the slow movement and there is some moral superiority attached to this position (Germann Molz, 2009). Slow travel options generally, though not always, take longer but this might not be negative as a slow traveller reflects:

Louise: It took a long time to get there, I suppose. It seemed to take two days. We had to cycle from here [Bournemouth] to Poole get on the ferry to St Malo and stay the night in a hotel there. The next day take two trains to further along the Brittany coast and then at the end of that we cycled about 15 miles to where we were going to stay. All of that was quite nice it took from Saturday morning to late Sunday afternoon to get to where we were going. I'm not complaining... it was really enjoyable. (Dickinson, Lumsdon \& Robbins, 2011, p. 291)

In the case of slow travel, travel itself is a core element of the tourist experience rather than an ancillary service using up valuable time (Dickinson and Lumsdon, 2010). A 24 hour train journey is not an arduous trip but an integral element of the slow travel experience during which a tourist will enjoy a restaurant meal, overnight accommodation, a changing landscape as it morphs before them and time with family or friends. "To live slowly... means engaging in 'mindful' rather than 'mindless' practices which makes us consider the pleasure or at least the purpose of each task to which we give our time" (Parkins, 2004, p. 364).

However, access to some forms of transport is only possible for those with 'time to spare'. "In opting for these modes rather than faster alternatives, there is a conscious trade-off between time and the quality of the experience" (Cass et al., 2004, p.120).

Klein (2004) has observed that SNCF's (the French national railway company) original TGV advertising focused on the 'speed and less time' message, that is, the view that travel time is wasted time. However, after several years the company realised it was 
"neglecting the time spent by its clients in its trains. The more comfortable furnishings of the latest generations of wagons, the effort to develop on-board services and the latest advertising campaign ('Take the time to spend less time') all indicate a reversal of the initial attitude, and current efforts to make the most of the travel time." (Klein, 2004, p. 260). Other studies of utility travel on trains and in cars indicate this time can be productive (Holley et al., 2008; Laurier, 2004) and Salomon and Mokhtarian (1998) identified 'excess travel' where people choose to travel further than they need to in their everyday lives. These studies have questioned the use of time saving in policy appraisal of infrastructure such as new roads. Holley et al. (2008) conclude that if travel time is not a cost to the employer then the benefit of reducing that time is less.

The experience of travel time is therefore multiple and varied. Although increasing speed of travel has been important in opening up new market-destination combinations, the varied experience and use of time during travel presents some opportunities for the future sustainable consumption of tourism as it may challenge the idea of wasted time during travel and thus reduce the pressure on fast transport modes.

\section{The sustainable consumption of tourism and time}

From the previous discussion three time forces can be identified. First, there is a growing middle class, affluent population working in post-Fordist organizations. Statistics reveal no clear trends towards more or less working time or leisure time. However, the distinction between working hours and leisure hours is reducing. Second, increased productivity could enable society to work (slightly) less, but history shows much increased productivity is used to increase income. Third, new conceptualizations of time play a greater role in society and there is erosion of traditional place and time bound structures. Each of these is now subject to further analysis of their implications for tourism consumption.

Increasingly affluent but time pressured population. Under this position it can be assumed that most of the gains in leisure time have been achieved and people will make choices about how to spend their leisure time from a growing range of options. This will increase free time pressure as people seek to pack in more opportunities, and lead to choices that are most time efficient (see Figure 1 for hypothetical scenarios). From a tourism perspective this implies a greater reliance on air and car travel, with a potential shift to high speed rail where infrastructure is available. Tourists would be prepared to pay for luxury goods, as time is at a premium, with more intense use of resources in tourist consumption at destinations and during travel. This implies growing GHG emissions. This is the current tourism path where time is seen as a constraint.

On the other hand, as technology reaches a peak, greater speeds will be hard to achieve and time will limit distance, becoming a growing constraint and an indirect limit on GHG emissions. A society with seemingly infinite leisure choice may find it has less time to travel, though people may choose to spend time on an alternative carbon intensive activity. However, this point has not been reached because the average travel speed is still 
increasing since only a small share of the global population, some 2-5\% (Gössling \& Peeters, 2007), has access to air transport and thus speed may increase for the remaining population. Furthermore, even though the average speed of air transport is not increasing for a given distance, there is still a shift towards larger average distances. A longer flight has relatively more time spent cruising and therefore a distinctly higher average speed than short flights (Peeters \& Landré, 2012), most likely causing a further increase of average travel speed and distances. Currently moves to limit travel are viewed negatively. Time might be an indirect mechanism that limits travel in the future. There are significant industry implications of this perspective. Tourists are most able to adapt their behaviour to places near to home that can be accessed quickly. Some destinations might be better able to capture the time squeezed tourist due to proximate markets and availability of high speed surface infrastructure. Tour operators have already developed packages aimed at this market. Other destinations may decline. This only holds as long as sub sonic flight is the end of technological development. With developments in commercial space flight, the most affluent in society will be able to fly through space to the other side of the world in a mater of three to five hours, increasing speed by some $80-85 \%$. The impacts of commercial space flight might be very large as a recent study revealed that it would only take 1000 commercial space flights to cause the same amount of radiative forcing as all historic aviation since 1945 (Ross, Mills \& Toohey, 2010).

Increased productivity is taken as greater leisure time. Increased productivity could enable society as a whole to work less and, given the relative affluence of Western society, it is odd that more people do not already work less. To some extent the EU has gone further down this path than elsewhere with statutory employment law embedding holidays with pay, thus time is already less of a constraint. While it is difficult to stop people voluntarily over-working and working during holidays, even where there are statutory restrictions in place, a government policy to reduce over-employment is a possible option. This is a particularly attractive equity measure in countries where there is a widening poverty gap and high unemployment. This would result in more time availability but with static or lower incomes for the richer part of the population.

A greater availability of leisure time in itself may facilitate a reduction of time constraints and provide the opportunity for longer holidays, but social and other temporal constraints may remain. This could have varying impacts on GHG emissions (see Figure 2). On the one hand, tourists could opt for longer stays which would improve the eco-efficiency of tourism as the substantial travel emissions are averaged out over a longer period of time (see for example, Gössling et al., 2005; Peeters, Gössling \& Becken, 2006; Peeters \& Schouten, 2006). However, this will only work if the number of trips decreased. More time could also facilitate more of the current model which is shorter holidays, more frequently and of increasing distance. Other forces are also at work with a study of tourist happiness indicating that, due to pre-trip pleasure, a high frequency of short trips generates more happiness than few long trips (Nawjin, 2011). Therefore tourism emissions as a whole would continue to increase due to more tourism. Another impact might be that the number of trips stays the same, but that tourists opt for more sustainable modes of transport that take longer but have lower GHG emissions, the slow travel 
model. However, given that air and car travel are structurally embedded in tourism, leisure time is not the only factor to consider here, although Schor (2005) suggests a general decline in demand for speed when people have a time surplus.

Alternatively, more leisure time could lead tourism to more GHG emissions as more distant, exotic and time consuming travel becomes viable. The trend for young, educated, middle class people to travel the globe on a round the world air ticket and the extended holidays of retired people are obvious examples. This, of course, presupposes that tourists have the wealth to fund such travel. What is perhaps more likely is relatively inexpensive tourism, such as camping for several weeks, an option popular among Dutch tourists who have high levels of statutory paid holiday. Unlike the wider work on consumption (see, for example, Hayden and Shandra, 2009) lower environmental impact is not an obvious outcome of more time availability for tourism but it is a possible outcome. More has to change to reduce the environmental impacts of tourism. There are also concerns that while, in theory, policy could enable people to negotiate shorter working hours, there are established social norms about length of holidays and the 40 hour week that might be a barrier (Sanne, 2002).

Society enters a new time phase. The increasing release of society from traditional place and time bound structures may have significant implications for utility travel and recent data suggests a break of the link between GDP and travel (Department for Transport, 2009). The implications for tourist travel are of a different nature given that tourism, at least under current conceptualizations, is place related. It is not yet clear how this new phase of time will manifest itself in society except that time will be available in different packages with an increasing temporal and spatial fluidity. Current evidence points to new time structures as a strong force for unsustainable consumption. There are evidently opportunities for new forms of tourism that integrate work and leisure, since people are released from traditional spatial and temporal constraints that required co-presence for work. Since time is no longer fixed to the clock it ceases to be a constraint in the way it is currently understood. The question is whether this simply leads to more distant, fast travel, more often or slower, more GHG efficient travel.

Klein (2004) points out that in a fragmented time phase, speed is a necessity as it breaks down the barrier of distance, just as clock time sees speed as opportunity. Klein therefore views the move to a fragmented time phase as a further intensification of time use. This suggests less sustainable consumption. At the same time Southerton (2003) highlights the impact of increasing geographical mobility due to migration. This, together with a more globalised Network Society, can be a significant stimulus for visiting friends and relatives (Larsen et al., 2007). These forces, while potentially positive for the tourism sector, do not bode well for GHG emission reductions (see Figure 3). Conversely, the emergence of a new time phase might open up the opportunities for a modal shift to less carbon intensive travel by train, coach, cycle or foot. A greater integration of tourism with tasks such as work could be facilitated during train use with its access to mobile technologies. In this way origin to destination travel is viewed more productively. 
The above analysis has focused on time, however, clearly this does not act alone on tourism practice and the three scenarios above assume stable or growing prosperity and ignores other economic forces such as increasing fuel cost. Tourism practice also emerges from historical patterns which are culturally determined and can vary significantly dependent on destination and origin of visitors. Norms emerge that govern the travel mode through tourist habituation and are reinforced by infrastructure provision. Therefore time is one of many forces that might drive environmental impacts. This analysis has also largely ignored the poor who travel less. Holden (2007) suggests that in order to achieve sustainable mobility, some sectors of society need to increase their travel to achieve a minimum level of mobility. The poor are not only excluded by travel costs but are also constrained by both availability of time and their degree of 'time sovereignty' which restricts when and how they access travel resources in a tourism context.

\section{CONCLUSION}

This paper set out to explore the relationship between time and sustainable tourism mobility. It has examined current and emerging temporalities and considered whether this might provide opportunities to enable lower GHG emission from tourism. The analysis makes a theoretical contribution in a number of respects. First, the availability of time is typically seen as a tourism constraint, however, an appraisal of social theory and time, tourism temporalities, current work time structures and the experience of travel time indicate time is less of a constraint in contemporary society. However, there is a paradox here as many people feel more stressed, use their additional time to do more and increase the intensity of their travel schedules. All this will increase tourism GHG emissions, although analysis of consumption more broadly (Hayden and Shandra, 2009) has found societies that work fewer hours lead to lower environmental impact.

The analysis also illustrates how time adds to the structuration of society. There are degrees of time inequality in tourism mobility and it is evident that globally the majority are time poor. Much of the developing world lacks the time for tourism, while in the developed world, though some are time constrained, others inhabit fluid time in post modern society with a high degree of temporal flexibility and control. Much long-haul and long-stay tourism is only made possible by economic but also time inequality. Temporal issues are political and time is symbolic of power with some groups having much greater 'time sovereignty'. Overall, very few have the time to fly to exotic locations yet these tourists are responsible for the larger share of GHG emissions. At the same time, the appearance of slow travel in developed countries is predominantly a middle class phenomenon. This ignores the underclass and the population in developing countries who depend on slow modes of transport (public transport or even foot). The essential question here is whether slowness is a choice or not (Parkins, 2004). If slowness can be a choice, this is determined by how distance and time are valued.

Our thesis is that a new cognition of time and distance is required to facilitate sustainable tourism. A GHG constrained world implies a (air) travel constrained world (Peters \& Dubois, 2010) where the choice is between the current volume of aviation in combination 
with a strong increase of public transport and reduced car use, or maintaining car use at the expense of $80 \%$ of current air transport. The paper explored three time scenarios and their implications for tourism. On the whole the analysis is not optimistic for low carbon tourism. Analysis suggests new societal conceptualisations of time might facilitate more sustainable consumption patterns in tourism based around something like the 'slow travel' concept, where there is less air and car travel and more use of lower carbon forms of transport, shorter distances covered, longer stays at destinations and less frequent trips. This is due to a new phase of more fluid time releasing tourists from day to day temporal and spatial constraints. However, this is yet to materialise and policies restricting travel seem inevitable, as otherwise tourism is likely to continue on its growth trajectory of faster, more distant consumption, undertaken more often. In order to avoid significant danger from climate change the first route is needed. This route maintains tourism, since it does not necessarily reduce the number of trips, but a greater availability of time for travel enables tourists to engage more with the journey and utilise low carbon travel. More time would appear to be a condition to reach sustainable tourism with lower GHG emissions; however, availability of time is, on its own, not enough to achieve this end as alternative pathways are available. Reduced GHG emissions also requires less value to be placed on distant destinations and the tourist desire for "new possibilities of further, faster, everywhere and always" (Reisch, 2001, p. 376).

At this stage, the evidence and understanding of the role played by time is incomplete. While other areas of social science have been exploring new theoretical perspectives of time, further research is needed on the evolving role of time in tourism, especially tourism transport, and the opportunities available to establish a path to more sustainable travel. The following are recommended topics for further study.

The analysis here supports the calls of others (see for example, Gershuny, 2000) for more research to better understand public policy making on time regulation of elements such as holiday entitlement and work hours. Research needs to explore the relationship between working time and travel behaviour to establish whether these are related, to what extent, in what way and what this might mean for current tourism transport trends. Statistical time-series analysis of the relations between tourism and travel behaviour and time use could helpfully unravel the impacts of increased (and reduced) holiday time and other time use elements. Given the significant time inequity in tourism, there is a need for studies on lower socio-economic groups in society, that is, more studies on the working class and low income tourism in relation to use of time.

There is an overarching need for more analysis of how time is used and perceived by the tourist and especially the use of time during travel both to the destination and around the destination using a variety of modes. A specific focus would be in-depth research into the motivation and psychological values of 'slow travellers'; are their motivations and values different to the general tourist, in what respect and what would this mean for the development of slow travel and sustainable tourism development? Studies also need to explore the psychological value of physical, cultural and economic distance for tourists and the relative perception of time based in the past, present and future. Given that 
tourism usually requires future planning more research is needed to understand how people conceptualise their time allocation when booking travel for a future trip.

Research also needs to explore the role played by time stress during tourism, particularly the implications for travel behaviour, mode choice, destination choice and length of stay. To what extent are new time perspectives and multi-tasking influencing the 'natural' drive of people to seek the fastest transport mode available? How wide have new time perceptions spread over the global population and to what extent have work time and personal schedules become more fluid? Above all, as society's understanding of time evolves, new conceptual models of tourism travel are required. This is essential to understand and manage tourism's climate change impacts in order to evolve a sustainable pathway for tourism development.

\section{REFERENCES}

Alegre J, Pou L. 2006. The length of stay in the demand for tourism. Tourism Management 27: 1343-1355.

Adam B. 1995. Timewatch: The Social Analysis of Time. Cambridge: Polity Press.

Bærenholdt JO, Haldrup M, Larsen J, Urry J. 2004. Performing Tourist Places. Aldershot: Ashgate.

Barros CP, Machado LP. 2010. The length of stay in tourism. Annals of Tourism Research 37(3): 692-706.

Becken S, Hay JE. 2007. Tourism and climate change: risks and opportunities. Clevedon: Channel View Publications.

Bows A, Anderson K, Peeters P. 2009. Air Transport, Climate Change and Tourism. Tourism and Hospitality Planning \& Development 6(1): 7-20

Breedveld K. 1996. Post-Fordist leisure and work. Loisir et Société/ Society and Leisure 19(1): 67-90.

Brett JM, Stroh LK. 2003. Working 61 Plus Hours a Week: Why Do Managers Do It? Journal of Applied Psychology 88(1): 67-78.

Cass N, Shove E \& Urry J. 2004. Transport infrastructures: a social-spatial-temporal model, In Sustainable Consumption: The implications of changing infrastructures of provisionSoutherton D, Chappells H \& Van Vliet B (eds). Cheltenham, Edward Elgar; 113-129.

Cass N, Shove E \& Urry J. 2005. Social exclusion, mobility and access. The sociological review 53(3), 539-555.

Castells M. 1997. The power of identity. Oxford: Blackwell.

Castells M. 2000. The Rise of the Network Society, 2nd ed. Oxford: Blackwell.

Cohen, S. 2011. Lifestyle travellers: Backpacking as a way of life. Annals of Tourism Research, 38 (4), pp. 1535-1555.

Cohen SA, Higham JES, Cavaliere CT. 2011. Binge flying: Behavioural addition and climate change. Annals of Tourism Research doi:10.1016/j.annals.2011.01.013. 
Deem R. 1996. No time for a rest? An exploration of women's work, engendered leisure and holidays. Time and Society 5(1): 5-25.

Department for Transport. 2009. Transport Trends 2009 Edition. London: Departnment for Transport.

Dickinson JE, Lumsdon L. 2010. Slow Travel and Tourism. London: Earthscan.

Dickinson JE, Robbins D, Lumsdon L. 2010. Holiday travel discourses and climate change. Journal of Transport Geography 18: 482-489.

Dickinson JE, Lumsdon L, Robbins D. 2011. Slow travel: issues for tourism and climate change. Journal of Sustainable Tourism 19(3): 281-300.

Echtelt PE, Glebbeek AC, Lindenberg SM. 2006. The new lumpiness of work: explaining the mismatch between actual and preferred working hours. Work, Employment and Society 20(3): 493-512.

Edensor T. 2010. Introduction: Thinking about Rhythm and Space. In Geographies of Rhythm: Nature, Place, Mobilities and Bodies, Edensor E (ed). Farnham, Ashgate Publishing Group; 1-18.

Edensor T, Holloway J. 2008. Rhythmanalysing the coach tour: the Ring of Kerry, Ireland. Transactions of the Institute of British Geographers 33: 483-501.

Elsrud T. 1998. Time creation in traveling: The taking and making of time among women backpackers. Time and Society 7(2): 309-334.

Eurostat. 2010. The European Union Labour Force Survey. Available at http://epp.eurostat.ec.europa.eu/portal/page/portal/employment_unemployment_lf s/introduction (accessed 13th July2010).

Frändberg L. 2008. Paths in transnational time-space: Representing mobility biographies of young Swedes. Geogr. Ann. B 90(1): 17-28.

Füssel H.-M. 2010. How inequitable is the global distribution of responsibility, capability, and vulnerability to climate change: A comprehensive indicator-based assessment. Global Environmental Change 20(4): 597-611.

Gershuny J. 2000. Changing Times: Work and Leisure in Postindustrial Society. Oxford: Oxford University Press.

Germann Molz JG. 2009. Representing pace in tourism mobilities: Staycations, Slow Travel and The Amazing Race. Journal of Tourism and Cultural Change 7(4): 270-286.

Germann Molz J. 2010. Performing Global Geographies: Time, Space, Place and Pace in Narratives of Round-the-World Travel. Tourism Geographies 12(3): 329-348.

Golden L. 2009. A Brief History of Long Work Time and the Contemporary Sources of Overwork. Journal of Business Ethics 84: 217-227.

Gössling S. \& Peeters PM. 2007. "It does not harm the environment!” An analysis of industry discourses on tourism, air travel and the environment. Journal of Sustainable Tourism 15(4): 402-417.

Gössling S, Peeters P, Ceron JP, Dubois G, Patterson T, Richardson RB. 2005. The ecoefficiency of tourism. Ecological Economics 54: 417-434.

Gössling S, Upham P. 2009. Introduction: Aviation and Climate Change in Context. In Climate Change and Aviation: Issues, Challenges and Solutions, Gössling S and Upham P (eds). London: Earthscan; 1-23. 
Gratton C. 1996. Work, Time and Leisure in Europe: National Differences and European Convergence. In Work Leisure and the Quality of Life, Gratton C (ed). Sheffield: Leisure Industries Research Centre; 53-67.

Haldrup M. 2004. Laid-Back Mobilities: Second-Home Holidays in Time and Space. Tourism Geographies 6(4): 434-454.

Hares E, Dickinson J, Wilkes K. 2010. Climate change and the air travel decisions of UK tourists. Journal of Transport Geography 18, 466-473.

Hayden A, Shandra JM. 2009. Hours of work and the ecological footprint of nations: an exploratory analysis. Local Environment 14(6): 575- 600.

Holden E. 2007. Achieving Sustainable Mobility: Everyday and Leisure-time Travel in the EU. Aldershot: Ashgate.

Holley D, Jain J, Lyons G. 2008. Understanding Business Travel Time and Its Place in the Working Day. Time Society 17(1): 27-46.

Holliday S. 1996. Trends in British Work and Leisure. In Work Leisure and the Quality of Life, Gratton C (ed). Sheffield: Leisure Industries Research Centre; 68-83.

Hupkes G. 1982. The law of constant travel time and trip-rates. Futures 14(1): 38-46.

Jäckel M, Wollscheid S. 2007. Time is Money and Money Needs Time? A Secondary Analysis of Time-Budget Data in Germany. Journal of Leisure Research 39(1): 86-108.

Jackson T. 2005. Live better by consuming less?: is there a "double dividend" in sustainable consumption? Journal of Industrial Ecology 9(1-2): 19-36.

Klein O. 2004. Social Perception of Time, Distance and High-Speed Transportation. Time \& Society 13(2/3): 245-263.

Larsen J, Urry J, Axhausen KW. 2007. Networks and tourism: mobile social life. Annals of Tourism Research 34(1): 244-262

Laurier E. 2004. Doing office work on the motorway. Theory, Culture and Society 21: 261-277.

Metz D. 2008. The limits to travel. How far will we go? London: Earthscan.

Minca C. 2009. The Island: Work, Tourism and the Biopolitical. Tourist Studies 9(2): 88108.

Nawijn J. 2011. Determinants of Daily Happiness on Vacation. Journal of Travel Research 50(5): 559-566.

Office of Population Censuses and Surveys. (1992). Labour Force Survey, 1991. Available at https://www.esds.ac.uk/ (accessed Aug 2010).

Office for National Statistics. 2010. Quarterly Labour Force Survey, January - March, 2010. Available at https://www.esds.ac.uk/ (accessed Aug 2010).

Organisation for Economic Co-operation and Development. 2010. OECD Statistics Extracts: Average hours actually worked per worker. Available at http://stats.oecd.org/Index.aspx?DataSetCode=ANHRS (accessed Aug 2010)

Parker S. 1983. Leisure and Work. London: George Allen Unwin.

Parkins W. 2004. Out of Time: Fast Subjects and Slow Living. Time and Society 13(2-3): 363-382.

Peeters P. 2007. Mitigating tourism's contribution to climate change - an introduction. In Tourism and Climate Change Mitigation: Methods, greenhouse gas reductions and policies Peeters P (ed). Breda: Stichting NHTV Breda: 11-26. 
Peeters PM, Dubois G. 2010. Tourism travel under climate change mitigation constraints. Journal of Transport Geography 18: 447-457.

Peeters P, Landré M. 2012. The emerging global tourism geography - an environmental sustainability perspective. Sustainability 4(1): 42-71.

Peeters P, Schouten F. 2006. Reducing the Ecological Footprint of Inbound Tourism and Transport to Amsterdam. Journal of Sustainable Tourism 14(2): 157-171.

Peeters P, Gössling S, Becken S. 2006. Innovation towards tourism sustainability: Climate change and aviation. Int. J. Innovation and Sustainable Development 1(3): 184-200.

Peeters PM., Dubois G. 2010. Exploring tourism travel under climate change mitigation constraints. Journal of Transport Geography 18: 447-457.

Peters P. 2006. Time, innovation and mobilities: travel in technological cultures. London: Taylor \& Francis.

Prideaux B. 2000. The resort development spectrum - a new approach to modeling resort development. Tourism Management 21: 225-240.

Prideaux B. 2002. Building Visitor Attractions in Peripheral Areas - Can Uniqueness Overcome Isolation to Produce Viability? International Journal of Tourism Research 4: 379-389.

Reisch LA. 2001. Time and Wealth: The role of time and temporalities for sustainable patterns of consumption. Time and Society 10(2/3): 367-385.

Richards G. 1998. Time for a holiday? Social rights and international tourism consumption. Time and Society 7(1): 145-160.

Ross MT, Mills M, Toohey D. 2010. Potential Climate Impact of Black Carbon Emitted by Rockets. Geophysical Research Letters 37: L24810, doi:10.1029/2010GL044548.

Salomon I, Mokhtarian PL. 1998. What happens when mobility-inclined market segments face accessibility enhancing policies? Transportation Research D 3(3): 129-140.

Sanne C. 2002.Willing consumers - or locked in? Policies for sustainable consumption. Ecological Economics 42(1-2): 273-287.

Schäfer A, Victor DG. 2000. The future mobility of the world population. Transportation Research - A 34: 171-205.

Schor J. 1991. The Overworked American: The unexpected Decline of Leisure. New York: Basic Books.

Schor J. 1996. Work, Time and Leisure in the USA. In Work Leisure and the Quality of Life Gratton C (ed). Sheffield: Leisure Industries Research Centre: 6-21.

Schor JB. 2005. Sustainable consumption and worktime reduction. Journal of Industrial Ecology 9(1-2): 37-50.

Scott D, Peeters P, Gössling S. 2010. Can tourism deliver its 'aspirational' greenhouse gas emission reduction targets? Journal of Sustainable Tourism 18 (3): 393 - 408.

Southerton D. 2003. 'Squeezing Time' Allocating practices, coordinating networks and scheduling society. Time \& Society 12(1): 5-25.

Southerton, D., Shove, E. \& Warde, A. (2001) 'Harried and Hurried': time shortage and the co-ordination of everyday life. Manchester: Centre for Research on Innovation and Computing, University of Manchester. 
United Nations. 2011. World Population Prospects: The 2010 Revision. New York, UN, Department of Economic and Social Affairs, Population Division.

UNWTO. 2011. UNWTO World Tourism Barometer (English version) 09(01): 1-57.

Urry J. 1994. Time, Leisure and Social Identity. Time and Society 3(2): 131-149.

Veijola S. 2009. Gender as Work in the Tourism Industry. Tourism Studies 9(2): 109-126.

Victor P. 2010. Questioning economic growth. Nature 468(7322): 370-371.

Wittmer A, Laesser C. 2010. The Perception of Time in Air transport - What a Delay is accepted by Air Travellers? Journal of Air Transport Studies 1(1): 48-61. 
Table 1. Average annual hours worked per worker for selected countries (full-time and part-time workers)

\begin{tabular}{lrrrrrrrrrr}
\hline Country & 1970 & 1980 & 1990 & 2000 & 2001 & 2002 & 2003 & 2004 & 2005 & 200 \\
\hline Canada & - & 1787 & 1756 & 1756 & 1751 & 1738 & 1727 & 1744 & 1734 & 173 \\
Denmark & 1855 & 1630 & 1515 & 1549 & 1554 & 1542 & 1540 & 1544 & 1548 & 155 \\
France & 1873 & 1699 & 1581 & 1491 & 1481 & 1445 & 1441 & 1469 & 1466 & 144 \\
Greece & - & - & 1736 & 1818 & 1826 & 1818 & 1812 & 1803 & 1811 & 179 \\
Hungary & - & 1930 & 1710 & 1795 & 1766 & 1766 & 1777 & 1807 & 1803 & 179 \\
Japan & - & - & 2064 & 1853 & 1836 & 1825 & 1828 & 1816 & 1802 & 181 \\
Netherlands & 1830 & 1581 & 1433 & 1331 & 1330 & 1317 & 1309 & 1309 & 1301 & 130 \\
United Kingdom & 1877 & 1713 & 1711 & 1690 & 1693 & 1678 & 1658 & 1652 & 1658 & 165 \\
United States & 1895 & 1815 & 1833 & 1835 & 1814 & 1810 & 1800 & 1803 & 1801 & 180 \\
\hline
\end{tabular}

Source: OECD 2010 
Table 2. Actual hours worked per week by employment category for UK full-time workers

\begin{tabular}{|c|c|c|c|c|c|c|c|c|}
\hline & 2000 & 2001 & 2002 & 2003 & 2004 & 2005 & 2006 & 2007 \\
\hline \multicolumn{9}{|l|}{ Armed forces } \\
\hline & 45.88 & 46.50 & 47.60 & 47.55 & 46.33 & 45.18 & 46.50 & 46.43 \\
\hline $\begin{array}{l}\text { Legislators, senior officials and } \\
\text { managers }\end{array}$ & 44.98 & 45.35 & 44.90 & 44.73 & 44.53 & 44.33 & 44.23 & 44.40 \\
\hline \multirow{3}{*}{$\begin{array}{l}\text { Technicians and associate } \\
\text { professionals } \\
\text { Clerks }\end{array}$} & 42.20 & 42.75 & 42.50 & 42.50 & 42.28 & 42.10 & 42.00 & 41.85 \\
\hline & 40.48 & 40.13 & 39.83 & 39.58 & 39.63 & 39.58 & 39.48 & 39.65 \\
\hline & 37.60 & 37.35 & 36.83 & 36.75 & 36.68 & 36.88 & 36.98 & 36.90 \\
\hline $\begin{array}{l}\text { Service workers and shop and } \\
\text { market sales workers }\end{array}$ & 40.43 & 39.93 & 39.40 & 39.28 & 39.13 & 39.18 & 39.05 & 39.03 \\
\hline $\begin{array}{l}\text { Skilled agricultural and fishery } \\
\text { workers }\end{array}$ & 48.10 & 49.73 & 48.45 & 48.13 & 48.80 & 47.70 & 47.63 & 48.75 \\
\hline Craft and related trades workers & 43.10 & 43.23 & 42.75 & 42.60 & 42.68 & 42.35 & 42.43 & 42.13 \\
\hline $\begin{array}{l}\text { Plant and machine operators and } \\
\text { assemblers }\end{array}$ & 44.00 & 43.68 & 43.48 & 43.50 & 43.40 & 43.03 & 43.23 & 43.25 \\
\hline \multirow{2}{*}{ Total } & 41.00 & 41.58 & 41.33 & 41.20 & 41.10 & 41.00 & 40.80 & 41.08 \\
\hline & 42.71 & 42.93 & 42.61 & 42.49 & 42.36 & 42.06 & 42.14 & 42.25 \\
\hline
\end{tabular}

Source: Eurostat 2010

Table 3. Variability in weekly hours (Labour Force Survey 1991 and 2010)

\begin{tabular}{lrrrr}
\hline & 1991 & \multicolumn{2}{c}{2010} \\
& $\mathrm{n}$ & $\%$ & $\mathrm{n}$ & $\%$ \\
\hline Weekly hours vary & 26666 & 42.8 & 16245 & 40.7 \\
Weekly hours same & 35600 & 57.2 & 23712 & 59.3 \\
Total & 62266 & & 39957 & \\
\hline
\end{tabular}

Source: Office for National Statistics 2010: Office of Population Censuses and Surveys 1992 
Table 4. Hours of paid/unpaid overtime (Labour Force Survey 1991 and 2010)

\begin{tabular}{lll}
\hline & mean & Std. Deviation \\
\hline Actual paid overtime hours & & \\
1991 & 3.24 & 6.561 \\
2010 & 3.06 & 10.920
\end{tabular}

Actual unpaid overtime hours

1991

2010

Source: Office for National Statistics 2010; Office of Population Censuses and Surveys 1992

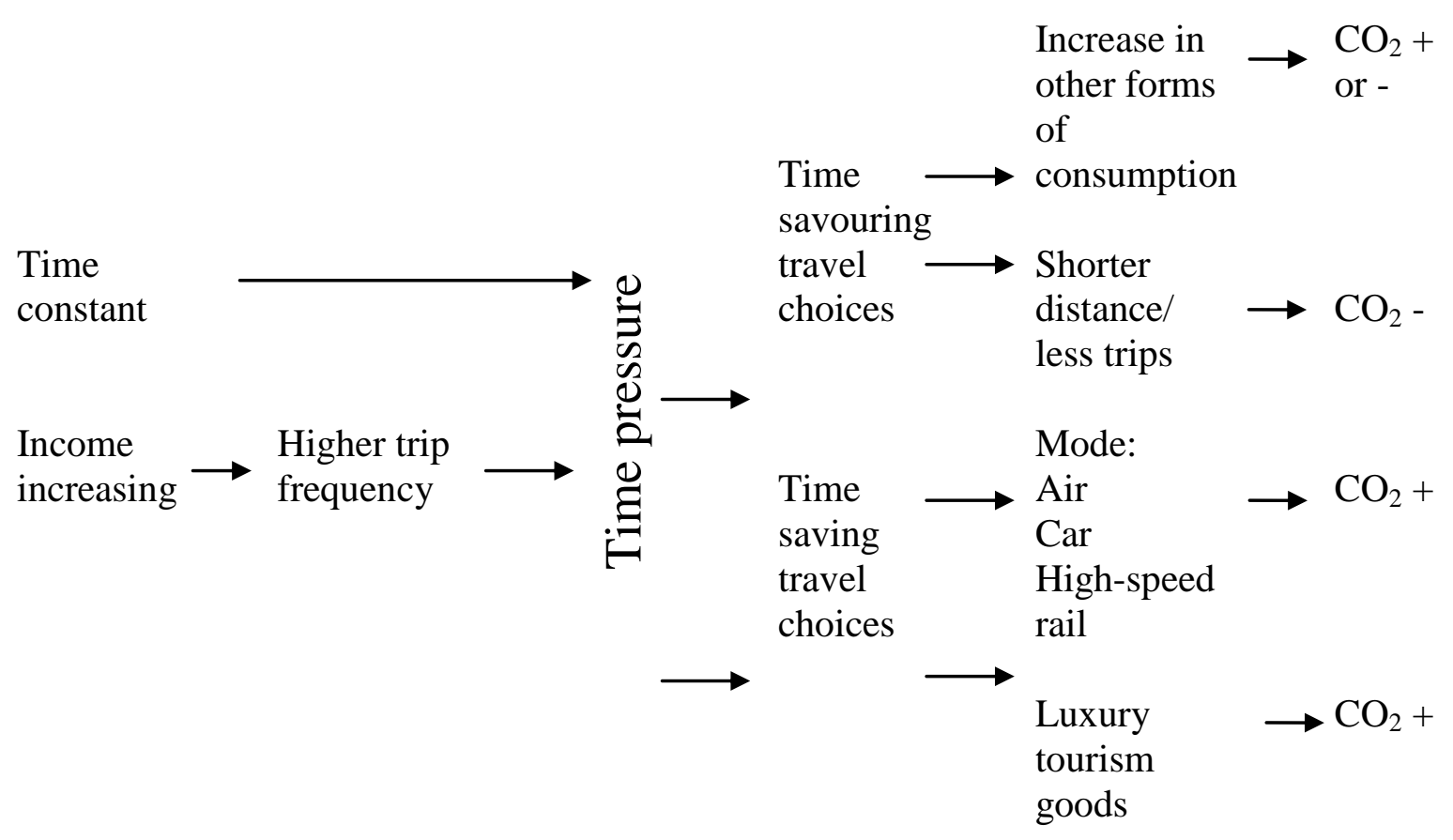

Figure 1. Hypothetical tourism consumption scenarios and $\mathrm{CO}_{2}$ outcomes assuming an increasingly affluent but time pressured population. 


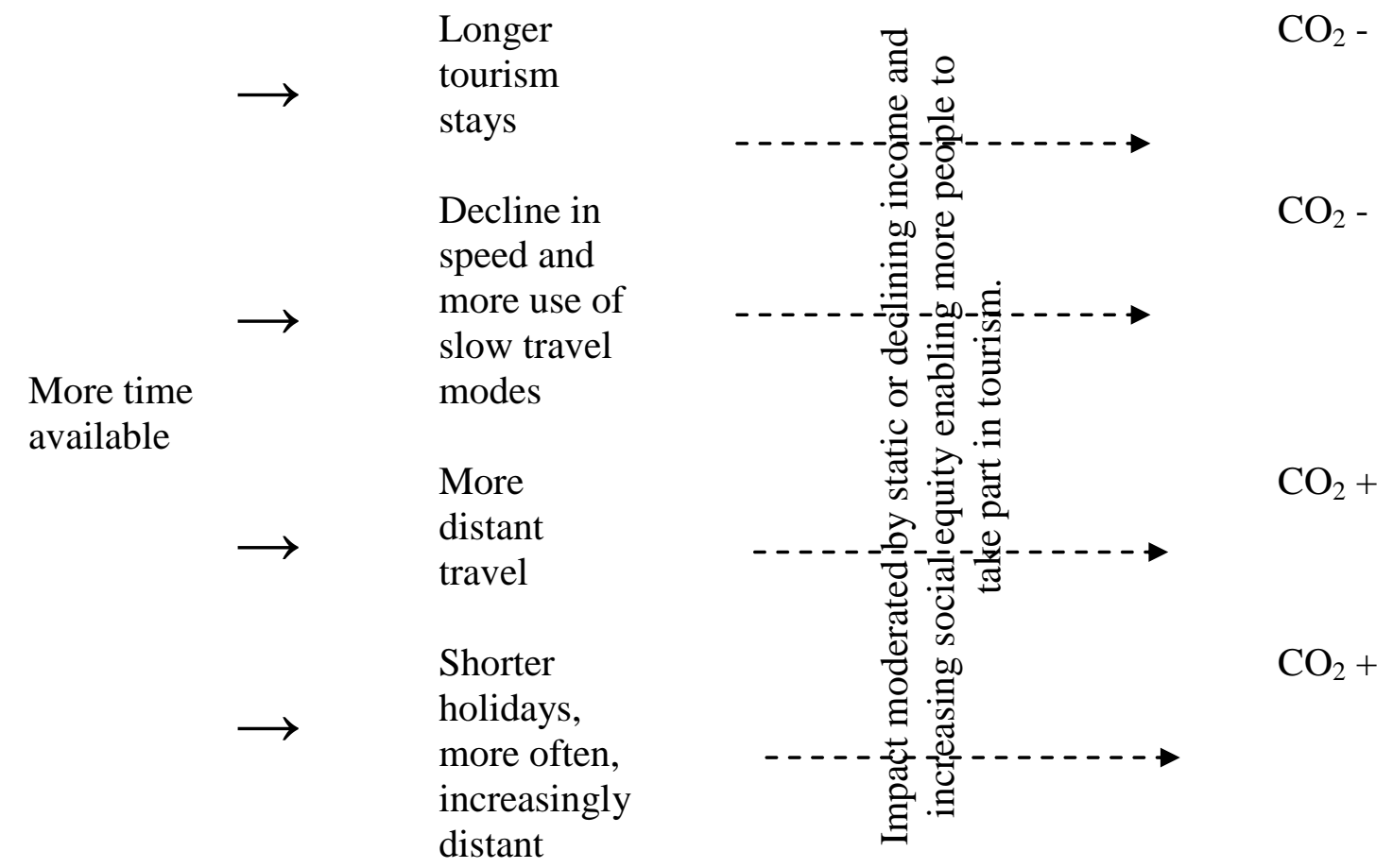

Figure 2. Hypothetical tourism consumption scenarios and $\mathrm{CO}_{2}$ outcomes assuming increased productivity is taken as more leisure time.

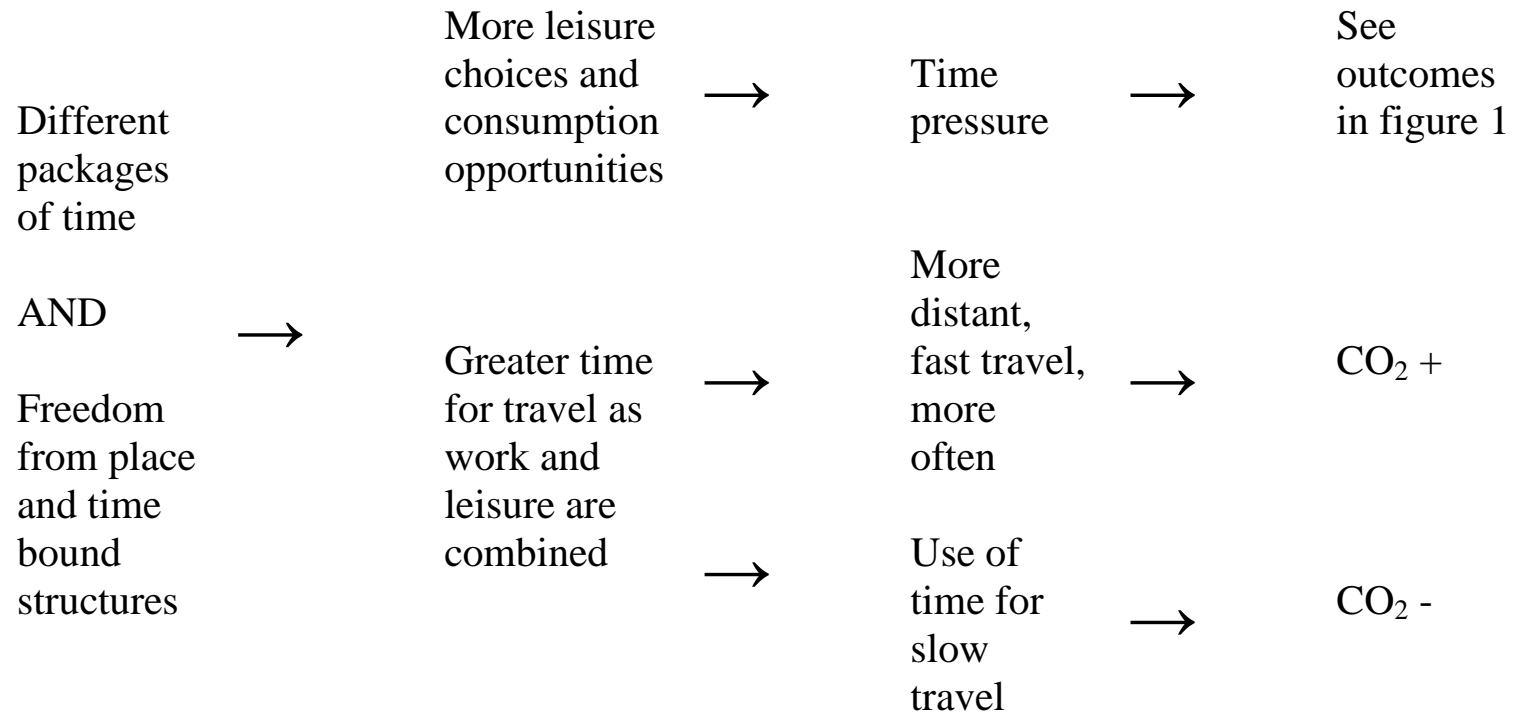

Figure 3. Hypothetical tourism consumption scenarios and $\mathrm{CO}_{2}$ outcomes assuming society enters a new time phase 